\title{
Sobre los dos sentidos del concepto habermasiano de sociedad postsecular*
}

\author{
On two meanings of Habermas' \\ concept of a post-secular society
}

LEONARDO RODRÍGUEZ DUPLÁ**

\begin{abstract}
Resumen: Habermas se ha valido a menudo de la expresión "sociedad postsecular" para referirse al proceso de aprendizaje mutuo entre la razón ilustrada y la conciencia religiosa en el seno de las sociedades modernas. Esa expresión es utilizada por el pensador alemán en dos acepciones distintas. Una veces la emplea como categoría sociológica descriptiva y otras como categoría filosófica de carácter normativo. En este trabajo rechazamos el uso descriptivo del concepto de sociedad postsecular, haciéndonos eco de las críticas que contra él se han vertido desde la sociología de la religión contemporánea. A la vez, reconocemos el interés que reviste la propuesta normativa de Habermas. Tras exponer el sentido preciso de esa propuesta, examinamos la principal acusación que contra ella cabe formular: la de funcionalismo religioso.
\end{abstract}

Palabras clave: Habermas, sociedad postsecular, religión, Modernidad, funcionalismo.

\begin{abstract}
Habermas has often used the phrase "post-secular society" in reference to the process of mutual learning between enlightened reason and religious consciousness that takes place in modern societies. That phrase is used by him in two different senses. Sometimes he uses it as a descriptive sociological notion, sometimes as a normative philosophical category. In rejecting the descriptive use of the concept of a post-secular society, this paper echoes some objections raised by recent work in the sociology of religion. On the other side, a positive value is accorded to Habermas' normative proposal. After expounding the precise meaning of that proposal, we discuss the main charge that can made against it: the charge of religious functionalism.
\end{abstract}

Keywords: Habermas, post-secular society, religion, modernity, functionalism.

Fecha de recepción: 17/03/2015. Fecha de aceptación: 25/06/2015.

* Trabajo realizado en el marco del proyecto de investigación FFI2015-63794-P del Ministerio de Economía y Competitividad.

** Profesor titular de Filosofía Moral de la Universidad Complutense de Madrid. Sus principales líneas de investigación son la ética y la antropología de Scheler y la filosofía de la religión de Kant. Entre sus trabajos recientes destacan "Zur Begründung der These Max Schelers vom Primat der Liebe”, Thaumàzein 3 (2015) pp. 287-304, y "Die Kohärenz der Gnadenlehre im kantischen Denken", que aparecerá próximamente en la revista KantStudien.Contacto: dupla@filos.ucm.es 


\section{Gestación de la idea de una sociedad postsecular}

El pensador alemán Jürgen Habermas empleó por primera vez en 2001 la expresión "sociedad postsecular" para referirse a un importante cambio que, a su juicio, se ha producido recientemente en la conciencia pública de las sociedades industriales modernas más intensamente secularizadas. ${ }^{1}$ A lo largo de los últimos decenios, estas sociedades habrían ido tomando conciencia de que la religión no es un mero vestigio del pasado, un anacronismo llamado a desaparecer, sino una realidad con la que hay que seguir contando. Esta circunstancia habría llevado a replantear en ellas la relación entre Modernidad y religión. En la sociedad postsecular, la razón secularizada alcanza un nuevo nivel reflexivo al emprender un diálogo con las tradiciones religiosas, diálogo que, según veremos, Habermas concibe como un proceso de aprendizaje mutuo.

La amplia resonancia que alcanzó esta idea desde que fuera presentada en 2001 se explica en buena medida por haber sido propuesta precisamente por Habermas, un adalid de la razón ilustrada que siempre se ha mostrado ajeno a toda fe religiosa. Si bien la sorpresa inicial fue grande, no tardó en advertirse que la idea de una sociedad postsecular se venía gestando desde hacía mucho en el pensamiento de Habermas. En esa idea cristalizaba el progresivo cambio de actitud hacia la religión que cabe rastrear en las obras de este autor. Al explicar este importante cambio en la posición de Habermas, los especialistas suelen distinguir tres fases en la evolución de su pensamiento. ${ }^{2}$

(1) El texto más representativo de la primera fase es Teoría de la acción comunicativa, que vio la luz en 1981. ${ }^{3}$ En esta obra se sostiene, en la estela de Max Weber, que la secularización ha sido el factor decisivo en el origen y desarrollo de la Modernidad. Habermas hace suyo asimismo el pronóstico negativo de Weber acerca del futuro de la religión, que terminará desapareciendo en virtud del imparable proceso de "desencantamiento del mundo".

Para Habermas, el rasgo distintivo del período histórico moderno consiste en que en él ya no existe una "imagen del mundo" unificada. La religión no constituye ya el centro de gravedad capaz de mantener unida y cohesionada la cultura occidental. El ámbito de lo sagrado ha sido progresivamente desencantado y depotenciado merced a la activación de las competencias comunicativas generales, es decir, la capacidad para buscar el entendimiento con los otros y alcanzar un consenso basado en argumentos. "El aura de arrebato y terror que irradia de lo sagrado, la fuerza fascinante de lo santo, se subliman y vuelven cotidianas al convertirse en fuerza vinculante de pretensiones de validez expuestas a la crítica" ${ }^{4}$. La progresiva sustitución de la autoridad de lo santo por la autoridad del consenso racional tiene consecuencias de largo alcance. Se produce, por un lado, la diferenciación o desgajamiento

1 Cf. J. Habermas, Glauben und Wissen, Suhrkamp, Frankfurt, 2001. La expresión "sociedad postsecular" se aplica a muchas naciones de Europa Occidental, pero también a algunos países en cuya formación la emigración europea ha sido determinante, como Canadá o a Australia.

2 Cf. Klaus Thomalla, "Bedeutung und Grenzen der Habermas'schen Religionsphilosophie", en: W. Schweidler (Hg.), Postsäkulare Gesellschaft, Alber Verlag, Freiburg / München, 2007, pp. 115-147; T.M. Schmidt, "Gibt es eine moderne Religion? Jürgen Habermas und die Idee der 'postsäkularen Gesellschaft", Forschung Frankfurt 2 (2009) pp. 64-67; S. Maly, "Die Rolle der Religion in der postsäkularen Gesellschaft", Theologie und Philosophie 80 (2005), pp. 546-565.

3 Cf. J. Habermas, Theorie des kommunikativen Handelns, Suhrkamp, Frankfurt, 1981.

4 Op. cit., II, p. 119. 
(Ausdifferenzierung) de la ciencia, la moral y el arte como esferas independientes, no sometidas a tutelas ni puestas al servicio de fines que les son extraños; por otro, la privatización de la religión, que es gradualmente desalojada del dominio público y remitida al ámbito de la conciencia individual. En la perspectiva weberiana asumida por Habermas a comienzos de los años 80, Modernidad y religión son magnitudes enfrentadas. Su relación puede ser descrita como un "juego de suma cero", en el que una parte sólo prospera a expensas de la otra. Y como el desarrollo social era concebido por él a esas alturas como un proceso unidireccional e imparable, Habermas pensaba que la desaparición definitiva de la religión en el mundo moderno era sólo cuestión de tiempo.

(2) La segunda fase en la evolución del pensamiento de Habermas sobre la religión comienza a finales de los años 80 y se caracteriza por el abandono, cada vez más explícito, de la teoría del desarrollo social expuesta en Teoría de la acción comunicativa. En el volumen de ensayos titulado Pensamiento postmetafísico, se marca un punto de inflexión al sugerirse que la filosofía "no puede sustituir ni desalojar a la religión"5. Al menos no podrá hacerlo en tanto "el lenguaje religioso transmita contenidos semánticos inspiradores, contenidos irrenunciables que se sustraen (¿por ahora?) a la fuerza expresiva de un lenguaje filosófico y esperan a ser traducidos en discursos que los fundamenten"6. No hace falta encarecer la importancia de la pregunta formulada entre paréntesis. Es la prueba de que, al redactar las líneas citadas, Habermas no tiene todavía del todo claro si el discurso filosófico será capaz un día de reemplazar por completo los contenidos valiosos del lenguaje religioso que hoy se le resisten. Pero lo cierto es que, en textos posteriores de esta segunda fase, la filosofía es presentada cada vez más como una colaboradora imparcial que ayuda a mediar en las disputas religiosas, y no como la fuerza colonizadora que intenta desalojar a las tradiciones religiosas de las posiciones que éstas ocupan en la esfera pública. Esto es particularmente claro en una conferencia de 1995 titulada "La lucha de los poderes religiosos"7. Aquí se sostiene que la superación de las tensiones entre las comunidades creyentes sólo es posible si esas comunidades se someten a un proceso reflexivo que les permita asumir los logros irrenunciables de la Modernidad y de este modo las capacite para la convivencia pacífica en el seno de una sociedad pluralista. En este proceso de modernización de la conciencia religiosa, la filosofía, como saber imparcial, puede prestar un servicio impagable apoyándose en su propia experiencia histórica: "La filosofía, que ha recorrido el camino de la Ilustración y se ha confrontado con sus propios orígenes metafísicos, explica la diferencia entre la religión antes y después de la Ilustración"8.

(3) La tercera etapa se inicia en 2001 con la ya citada conferencia "Creer y saber". En la nueva posición adoptada por Habermas, las dudas sobre el futuro de la religión parecen por fin resueltas: no sólo se cuenta con la permanencia de las comunidades religiosas en el seno de las sociedades modernas, sino que el hecho de contar con esa permanencia es considerado el rasgo distintivo de la sociedad postsecular. A la vez, la razón emancipadora se vuelve consciente de sus límites: cae en la cuenta de que el proceso de secularización, dejado a su

5 J. Habermas, Nachmetaphysisches Denken, Suhrkamp, Frankfurt, 1988, p. 60.

6 Ibid.

7 J. Habermas, "Vom Kampf der Glaubensmächte. Karl Jaspers zum Konflikt der Kulturen”, en: Id., Vom sinnlichen Eindruck zum symbolischen Ausdruck. Philosophische Essays, Suhrkamp, Frankfurt, 1997, pp. 41-58.

8 Op. cit., p. 47. 
propia dinámica, tiende a provocar un vaciamiento normativo que amenaza con destruir los mejores logros de la Modernidad. Para evitar que la secularización descarrile, víctima de su propio éxito, la razón ilustrada tiene que mostrarse "dispuesta al aprendizaje" (lernbereit) 9 , es decir, tiene que salir de sí misma para encontrar recursos normativos que compensen sus tendencias autodestructivas. Esta nueva actitud la llevará al encuentro de aquellas tradiciones religiosas en las que, con el correr de los siglos, se ha ido depositando un caudal de intuiciones morales capaces de interpelar incluso a quienes carecen de sensibilidad religiosa, intuiciones morales que, hasta el presente, la razón moderna no ha sido capaz de articular en su propio lenguaje. La tarea que hoy debe afrontar la razón secularizada en el marco de una sociedad postsecular consiste precisamente en intentar "traducir" a un lenguaje accesible a todos, creyentes y no creyentes, los contenidos normativos presentes en las religiones que todavía no han sido recibidos por la conciencia moderna. Dicho con palabras del propio Habermas: "Una secularización no aniquiladora se realiza en el modo de la traducción"10.

En beneficio de esta propuesta, el pensador alemán advertirá que no se trata en realidad de una estrategia novedosa, toda vez que la ósmosis semántica por la que la razón filosófica absorbe contenidos de la religión se ha dado siempre: por ejemplo, "el derecho igualitario de la razón tiene raíces religiosas". ${ }^{11}$ Con todo, hay indicios muy claros de que el proceso de asimilación por la razón de contenidos morales formulados originalmente en el lenguaje de las religiones no ha sido plenamente exitoso: "Cuando el pecado se transformó en culpa y las transgresiones de los mandatos divinos en infracciones de las leyes humanas, algo se perdió"12. La actual sociedad postsecular es precisamente la que cobra conciencia de este déficit y decide reactivar el proceso de traducción del potencial normativo de las religiones a un lenguaje universal. El éxito de esta empresa pasa por la colaboración entre ambas partes: la traducción que rescata para la razón intuiciones religiosas capaces de inspirar conductas solidarias es entendida por Habermas como un proceso de aprendizaje recíproco que plantea exigencias tanto a la razón secularizada como a la conciencia religiosa.

\section{El uso descriptivo del concepto de sociedad postsecular}

Una vez reconstruida a grandes rasgos la evolución del pensamiento de Habermas en lo tocante a la relación entre religión y Modernidad, nos centraremos en el análisis del concepto de "sociedad postsecular". Esto exigirá tener en cuenta los numerosos textos posteriores a 2001 en los que el prolífico pensador alemán ha continuado elaborando las ideas expuestas en la conferencia "Creer y saber", así como algunas reacciones críticas que su propuesta ha suscitado. Intentaremos mostrar que el concepto de sociedad postsecular reviste una complejidad que desaconseja aceptarlo o rechazarlo en bloque. Antes bien, debemos realizar el trabajo de desentrañar las distintas ideas que convergen en él, para poder valorarlas de manera independiente.

Se ha observado en ocasiones que la elección del término "postsecular" para designar la fase actual en el desarrollo de las sociedades más secularizadas de Occidente es poco afor-

9 Glauben und Wissen, p. 15.

10 Op. cit., p. 29.

11 Op. cit., p. 21.

12 Op. cit., p. 24. 
tunada, pues sugiere justamente lo contrario de lo que se quiere decir. ${ }^{13}$ Contra lo que invita a pensar el prefijo "post-", aquí no se pretende transmitir la idea de que en esas sociedades se haya alcanzado ya el final del largo proceso histórico conocido con el nombre de secularización, ni menos aún se afirma el fracaso de ese proceso. Antes bien, lo que se pretende indicar con ese término es que se ha alcanzado un punto de inflexión dentro del proceso de secularización. Si hasta hace muy poco la secularización había consistido en la progresiva emancipación de los distintos aspectos de la vida social respecto a la tutela que sobre ellos ejercía la religión -emancipación reflejada de manera paradigmática en la separación de iglesia y Estado-, lo propio de una sociedad postsecular consistiría en que en ella la secularización toma un nuevo sesgo, caracterizado no por la crítica de las tradiciones religiosas sino por la búsqueda del diálogo con ellas. Habida cuenta de que el proceso de secularización continúa su andadura en las sociedades occidentales a las que se refiere Habermas, habría sido mejor evitar describirlas como sociedades postseculares.

Pero no nos quedemos en una mera discusión de palabras, sino prestemos atención a lo que con ellas se quiere decir. Cuando lo hacemos, no tardamos en darnos cuenta de que en la expresión "sociedad postsecular", tal como Habermas la utiliza, se dan amalgamadas dos dimensiones semánticas que es necesario distinguir. "Sociedad postsecular" es, por una parte, una categoría sociológica con la que se pretende describir la novedosa situación por la que hoy atraviesan ciertas sociedades occidentales. Por otra, es una categoría filosófica de carácter normativo. Con ella no se alude al curso efectivo de la historia occidental, sino al curso que esta historia debería tomar para evitar que se produzca un descarrilamiento de la secularización. Salta a la vista que estas dos acepciones de "sociedad postsecular" no sólo son bien distintas, sino que ni siquiera se implican mutuamente. En lo que sigue sostendremos que la propuesta normativa de una sociedad en la que la razón moderna y la conciencia religiosa se comprometan en un proceso de aprendizaje recíproco reviste un gran interés; en cambio, rechazaremos la tesis descriptiva según la cual las sociedades modernas aludidas han iniciado recientemente ese proceso de diálogo y aprendizaje mutuo. Comencemos por esto último.

El modo como Habermas entiende la relación entre religión y Modernidad ha sido vigorosamente criticado por algunos de los más prestigiosos sociólogos de la religión contemporáneos. Por ejemplo, José Casanova, investigador español de la Universidad de Georgetown, admite que la religión ha visto recortado su ámbito de influencia directa en el mundo moderno, pero niega que esta pérdida de funciones de la religión se haya traducido en una disminución proporcional de su importancia social. ${ }^{14}$ Antes bien, la religión habría adoptado nuevas formas de presencia que le han permitido conservar buena parte de su influencia en la esfera pública incluso en los países en los que se ha registrado una considerable disminución cuantitativa de la praxis religiosa. Aun sin entrar en el detalle de los estudios empíricos que han llevado a Casanova a defender esta teoría, parece forzoso reconocer que su posición recibe un considerable apoyo intuitivo de numerosos fenómenos que hoy se registran en la vida pública de países presuntamente muy secularizados. Pensemos,

13 Cf. M. Knapp, “Glauben und Wissen bei Jürgen Habermas”, Stimmen der Zeit 226 (2008) pp. 270-280.

14 Cf. J. Casanova, Public Religions in the Modern World, Chicago University Press, Chicago, 1994; Id., Europas Angst vor der Religion, Berlin University Press, Berlín, 2009. 
por ejemplo, en la polémica alemana sobre la presencia del crucifijo en las aulas escolares, o en la discusión española sobre la enseñanza de la religión, o en los debates sobre cuestiones bioéticas en los que las iglesias cristianas han participado intensamente. La intensidad con la que se han desarrollado estas discusiones públicas atestigua el vigor que conserva la conciencia religiosa en las modernas sociedades occidentales.

Otro crítico muy conocido del paradigma weberiano de la secularización asumido por Habermas a comienzos de los años 80 es el sociólogo de la religión alemán Hans Joas. ${ }^{15}$ A su juicio, la prueba más palmaria de que religión y Modernidad no son realidades antagónicas la aporta el análisis de la sociedad estadounidense. Es muy sabido que en Estados Unidos, el país moderno por antonomasia, la religión conserva una extraordinaria vitalidad. Los estudios empíricos revelan que, a diferencia de lo ocurrido en Europa Occidental, en Estados Unidos el nivel de compromiso religioso de la ciudadanía no ha disminuido en el período que comprende desde el final de la Segunda Guerra Mundial hasta el presente, sino que se ha mantenido más o menos constante. Por su parte, la investigación histórica enseña que la religiosidad norteamericana no se ha mantenido a pesar de la adopción de un sistema político moderno; antes bien, la fundación del Estado americano a finales del siglo XVIII supuso un poderoso acicate para el despliegue público y privado de la conciencia religiosa.

Entre los intelectuales europeos ha sido frecuente considerar la religiosidad estadounidense como una excepción, un caso exótico que se puede explicar a partir de la peculiar génesis histórica de la nación americana. Pero, a juicio de Hans Joas y de muchos otros sociólogos, esta opinión queda desmentida tan pronto como consideramos el fenómeno religioso a nivel mundial. ${ }^{16}$ Aunque con ritmos muy diversos, el proceso de modernización se va extendiendo imparablemente por todos los rincones del planeta, espoleado por la globalización de la economía y las comunicaciones. Si la interpretación habermasiana de la modernidad fuera válida, los cambios a nivel mundial en términos de industrialización, urbanización y aumento del nivel cultural deberían ir acompañados de un claro retroceso de la práctica religiosa. Sin embargo, ha ocurrido lo contrario. Los estudios sociológicos revelan que, a nivel mundial, todas las grandes religiones han conservado o aumentado su vitalidad a lo largo de los últimos decenios. De aquí se sigue que el verdadero caso excepcional no es el de los Estados Unidos, sino el de algunos países europeos occidentales. ${ }^{17}$ Vista a esta luz, la tesis tradicional del antagonismo entre religión y Modernidad sería una prueba de que el pensamiento del Viejo Continente padece un lamentable eurocentrismo, que le lleva a proyectar sus propias experiencias -reales o soñadas- al resto de las culturas.

La consecuencia que se sigue de estas críticas es que el predicado "postsecular" no puede emplearse legítimamente como categoría sociológica. Recuérdese que con ese término se pretende describir un cambio con respecto a la situación en la que hasta hace poco se encontraban ciertas sociedades del mundo desarrollado. Pero la mayor parte de los sociólogos de la religión contemporáneos opina que en realidad esa situación previa nunca se ha dado. Entiéndase bien esto: no se trata de negar el fenómeno de la seculariza-

15 Cf. H. Joas, "Eine Rose im Kreuz der Vernunft", Die Zeit, 7 de febrero de 2002.

16 Cf. J. Casanova / H. Joas (Hg.), Die umstrittene Moderne, Kohlhammer, Stuttgart, 2010.

17 Cf. P. Berger (Hg.), The Desecularization of the World: A Global Overview, Eerdmans Publishing Company, Grand Rapids, 2005. 
ción como tal, sino más bien la caracterización de este fenómeno que hace de la religión enemiga irreconciliable de la Modernidad y en consecuencia anuncia su desaparición en las sociedades modernas. Y si la sociedad secularizada, en el sentido de Habermas, nunca se ha dado, tampoco puede haberse producido el cambio al que él alude con la expresión "sociedad postsecular", por la sencilla razón de que lo que no existe tampoco puede cambiar o dejar de existir.

El ya citado Hans Joas ha sido particularmente tajante en su rechazo del uso sociológico de este concepto. Se recordará que cuando Habermas presentó en 2001 su novedosa idea de una sociedad postsecular definió ésta como aquella sociedad que, a diferencia de lo que ocurría hasta hace poco, cuenta con el hecho de que las comunidades religiosas van a seguir existiendo. Pero, como señala Joas, en ninguna sociedad europea, por moderna que sea, ha sido dominante la idea de que la religión estaba próxima a su desaparición. Es cierto que sí lo creían algunos intelectuales laicos europeos, entre ellos Habermas. Lo que de todo ello se desprende no es que las sociedades europeas hayan cambiado, sino que ha cambiado, y mucho, el propio Habermas. ${ }^{18}$ Esto último lo reconocen todos los conocedores de su dilatada obra.

Las críticas al concepto de sociedad postsecular expuestas hasta ahora subrayan los defectos de la caracterización habermasiana de la situación previa al nacimiento de esa nueva sociedad. No nos hemos referido, sin embargo, al cambio de mentalidad que, según Habermas, se ha registrado recientemente en las sociedades europeas occidentales. Apoyándonos en esta circunstancia, cabría preguntar si el concepto de sociedad postsecular no conserva, pese a todos sus defectos, una cierta validez sociológica; no, desde luego, como descripción de la situación de la que venimos, sino como caracterización de la situación en la que nos hallamos en el presente. El cambio de mentalidad constitutivo de la sociedad postsecular consistiría en que se ha suscitado un nuevo clima de diálogo y búsqueda del entendimiento entre la razón secularizada y las tradiciones religiosas. De haberse producido un cambio tan importante, sería bueno disponer de un término con el que designarlo, y es aquí donde la expresión "sociedad postsecular" presenta su candidatura.

A nuestro juicio, este último intento de reivindicar el uso descriptivo de esa expresión no cuenta con un respaldo empírico suficiente. No se puede negar que se han dado, sobre todo en el nivel académico, ensayos interesantes de diálogo entre la fe religiosa y la razón ilustrada. Pero parece excesivamente optimista pensar que esa encomiable actitud dialogante de algunos intelectuales, entre ellos Habermas, sea un fiel reflejo del clima de opinión dominante en los países de Europa Occidental. Prueba de ello es la pujanza que exhibe, en la vida social y política europea, el laicismo extremo, firmemente empeñado en expulsar a la religión de la esfera pública. ${ }^{19} \mathrm{Y}$ no debemos ignorar que, del otro lado, también se registran en las comunidades creyentes actitudes inmovilistas que se cierran por principio a todo diálogo con la Modernidad.

18 Cf. H. Joas, "Eine Rose im Kreuze der Vernunft”, cit.

19 Cf. R. Spaemann, "Postsäkulare Gesellschaft", en: W. Schweidler (Hg.), Postsäkulare Gesellschaft. Perspektiven interdisziplinärer Forschung, Alber Verlag, Múnich, 2007, pp. 65-75. 


\section{El uso normativo del concepto de sociedad postsecular}

Pasemos a considerar la vertiente normativa del concepto de sociedad postsecular. No se trata ya de si se ha producido un cambio en la actitud que adoptan hacia la religión las sociedades más secularizadas de Occidente, sino de si ese cambio es deseable. Como sabemos, la respuesta de Habermas a esta última cuestión es afirmativa. Distanciándose de sus posiciones anteriores, este pensador ha llegado al convencimiento de que la razón moderna, dejada a su dinámica inmanente, puede terminar destruyendo sus más preciosas conquistas. Precisamente por ello, es imprescindible a su juicio que la secularización tome un nuevo rumbo y sea entendida ahora como un proceso de aprendizaje recíproco entre la razón ilustrada y las tradiciones religiosas. Para examinar adecuadamente esta propuesta, comenzaremos presentando los síntomas de "descarrilamiento de la Modernidad" que Habermas aprecia en la actual coyuntura histórica. Luego veremos cuáles son las exigencias que ese proceso de aprendizaje recíproco plantea a cada una de las partes implicadas.

El presente histórico está marcado por la globalización de la economía y las comunicaciones. La lógica del mercado invade todos los rincones del planeta y determina todas las dimensiones de la existencia individual y colectiva. Nuestra condición personal y nuestro modo de vida se definen cada vez más por el lugar que ocupemos en el sistema laboral y por nuestros hábitos de consumo. En las sociedades que han alcanzado un mayor índice de bienestar cunden el individualismo y la falta de compromiso político. El ciudadano se transforma progresivamente en homo oeconomicus, en sujeto monádico que persigue sus propios intereses y se parapeta detrás de sus derechos. Los vínculos interpersonales se entienden cada vez más en términos de relaciones contractuales. En el plano internacional, la política es cada vez más incapaz de regular las relaciones entre los pueblos. De hecho, los Estados han perdido buena parte de su protagonismo en el nivel internacional, en el que han hecho aparición otros global players, señaladamente las empresas multinacionales. Y no hay perspectivas de que avancemos hacia una juridificación de las relaciones internacionales que promueva eficazmente la justicia y garantice la paz entre los pueblos.

A todo esto se añade que, a impulsos de la globalización, la modernización de las formas de vida iniciada en Europa hace siglos se ha impuesto a marchas forzadas en otros contextos culturales. Lo que en Occidente ocurrió en un lento progreso de maduración histórica, en muchos otros lugares se ha llevado a cabo en unas pocas generaciones. La consecuencia inevitable es el sentimiento de desarraigo, de abrupta suspensión de vínculos sociales y tradiciones normativas vigentes hasta hace muy poco. Para colmo, las mismas potencias occidentales de las que procede el impulso modernizador disfrutan de un nivel de bienestar material incomparablemente más alto, en buena medida gracias a que la explotación del tercer mundo no ha cesado. La frustración que genera esta comprobación degenera fácilmente en violencia.

La cuestión es saber si la razón ilustrada cuenta con recursos propios suficientes para resolver estos problemas de los que ella misma, como motor de la Modernidad, es al menos parcialmente responsable. Habermas, el adalid del proyecto ilustrado, reconoce que hoy la razón incuba en su seno un derrotismo que hace muy difícil afrontar con confianza el futuro. ${ }^{20}$ Ese derrotismo

20 Cf. J. Habermas, "Ein Bewusstsein von dem, was fehlt. Über Glauben und Wissen und den Defaitismus der modernen Vernunft", Neue Zürcher Zeitung, 10 de febrero de 2007. 
se manifiesta de un modo visible en la amplia difusión del pensamiento postmoderno, para el que la dialéctica de la Ilustración ha terminado en fracaso. Pero incluso entre quienes conservan intacta su confianza en la razón humana se aprecia una fuerte tendencia a entender ésta como razón científico-técnica y, en consecuencia, a propugnar una visión naturalista del ser humano. Los problemas éticos con los que hoy nos confronta el desarrollo de la ingeniería genética son una de las manifestaciones más palpables e inquietantes de esta tendencia a la objetivación del hombre por la ciencia moderna. Como, por otra parte, la ciencia misma, como saber empírico que es, no puede aportar criterios normativos que regulen su despliegue imparable, parece claro que la razón moderna, entendida en esta clave cientificista, es parte del problema y de ningún modo la solución.

¿Cabe conjurar los peligros que hoy amenazan a la humanidad? Habermas da una respuesta matizada. Por una parte, está persuadido de que el "pensamiento postmetafísico", que es como él denomina a su propia posición, está en condiciones de enfrentarse con éxito al fuego cruzado de postmodernidad y naturalismo. A su juicio, la razón ilustrada es capaz de ofrecer una fundamentación suficiente del principio moral y de defender una imagen no naturalista del ser humano. Sin embargo, esta comprobación no debe llevarnos a un triunfalismo ingenuo, pues si bien es verdad que la victoria de la razón sobre su impugnación postmoderna y sobre el reduccionismo cientificista deja el camino expedito para la elaboración de una moral racional que dirija sus mandatos a la conciencia individual, también lo es que la razón moderna es incapaz de promover por sí sola el compromiso colectivo que reclama la aguda crisis contemporánea.

Merece la pena que nos demoremos unos instantes en este punto decisivo. A juicio de Habermas, las modernas éticas de la justicia son individualistas: sólo conocen deberes que se dirigen a la conciencia del individuo reclamando de él una conducta responsable. En condiciones normales, esas éticas ofrecen criterios de acción suficientes para afrontar las dificultades a las que se enfrenta la praxis política en el contexto de una sociedad democrática. Pero en situaciones de crisis como la nuestra, en las que las instituciones y los procedimientos democráticos se enfrentan a dificultades que escapan a su control, se hace imprescindible una actuación solidaria que les haga frente. El problema está en que las éticas de la justicia -pensemos en las elaboradas por Rawls o por el propio Habermas-, precisamente por su carácter individualista, no pueden hacer de la solidaridad un deber. Es precisamente este "déficit político" de las éticas de la justicia el que lleva a Habermas a volver la vista a las grandes tradiciones religiosas, en las que la solidaridad se alimenta de la conciencia de compartir un destino salvífico común, que en último término abraza a toda la humanidad. ${ }^{21}$

Apenas hace falta decir que el novedoso interés de Habermas por la religión no implica la aceptación por su parte de los contenidos dogmáticos de una determinada comunidad de fe. Su actitud personal sigue siendo la de un agnóstico. Como él mismo ha declarado, su propuesta de diálogo con las tradiciones religiosas "no tiene que ver con un cambio en mi apreciación personal de la religión [...], sino más bien con una apreciación más escéptica de la Modernidad". ${ }^{22}$ Tanto las crisis sociales ligada a la globalización, que favorece el paso de un mundo de sociedades nacionales a una sociedad mundial multicultural, como

21 Cf. J. Habermas, Nachmetaphysisches Denken II: Aufsätze und Repliken, Suhrkamp, Frankfurt, 2012, p. 131.

22 Op. cit., p. 213. 
los desafíos éticos planteados por las posibilidades eugenésicas inauguradas por la técnica genética, hacen dudoso que la razón secularizada, por sí sola, esté en condiciones de evitar el descarrilamiento de la Modernidad. Habida cuenta de la confesada "debilidad de la moral de la razón" 23 para afrontar los gravísimos desafíos actuales, el pensamiento postmetafísico no puede permitirse el lujo de ignorar el potencial moral presente en las tradiciones religiosas. Antes bien, ha de promover en el marco del Estado liberal un diálogo entre ciudadanos creyentes e increyentes que busque traducir a un lenguaje racional, accesible a todos, las percepciones morales aportadas por las tradiciones religiosas. Este diálogo es la manifestación política del proceso de "aprendizaje mutuo" que permite a la razón ilustrada y a la conciencia religiosa acceder a un nivel superior de reflexividad en el marco de la sociedad postsecular. A la naturaleza y condiciones de este proceso de aprendizaje nos referiremos a continuación.

\section{La secularización como proceso de aprendizaje recíproco}

El diálogo fructífero entre la razón secularizada y las comunidades religiosas sólo podrá tener lugar si ambas partes cumplen ciertas condiciones. El requisito más importante impuesto a la razón ilustrada es el abandono del laicismo beligerante que pretende expulsar a la religión de la esfera política y reducirla al ámbito privado. ${ }^{24} \mathrm{El}$ principal apoyo con que hoy cuenta el laicismo es la amplia difusión de la mentalidad naturalista, que hace de la ciencia empírica la única instancia de conocimiento autorizado y en consecuencia declara irracional toda creencia religiosa. Habermas, por su parte, ha denunciado incansablemente la objetivación cientificista de la condición humana promovida por el naturalismo, destacando su incompatibilidad con el modo como se entienden a sí mismos los ciudadanos en el marco del Estado liberal, a saber, como sujetos responsables de sus actos que buscan el entendimiento en condiciones de libertad e igualdad. Una consecuencia importante del rechazo del naturalismo es que no quepa excluir de antemano que las convicciones específicamente religiosas de las comunidades creyentes contengan un importante potencial cognitivo.

La deseable superación del laicismo presupone también el rechazo de un malentendido de orden político, también muy extendido. El Estado liberal moderno se caracteriza por su neutralidad cosmovisiva. Si por una parte se reconoce a todos los ciudadanos el derecho básico a la libertad de conciencia, por otra se afirma que el funcionamiento de las instituciones del Estado no está sometido a tutelas ideológicas o religiosas. Por ejemplo, los órganos deliberativos del Estado no pueden escamotear la discusión de una propuesta legislativa por el solo hecho de que su contenido sea contrario a los principios de una determinada comunidad religiosa, ni siquiera si ésta es mayoritaria. Esto supuesto, el error político a que nos referimos consiste en ignorar que también el laicismo es una ideología y, en consecuencia, proyectarla sobre las instituciones del Estado como si fuera parte de su sustancia normativa. Con ello no se salvaguarda la neutralidad del Estado, sino que se destruye. Es de la máxima importancia advertir que el Estado como tal no es "laico" en el sentido explicado, sino

23 J. Habermas, "Ein Bewusstsein von dem, was fehlt", cit.

24 Habermas reserva el término "Säkularismus" para referirse a este tipo de laicismo, del que él mismo se distancia expresamente. Cf. la aclaración terminológica en J. Habermas, Nachmetaphysisches Denken II, p. 324. 
neutral; quienes son laicos son algunos ciudadanos, mientras que otros profesan creencias religiosas. El Estado liberal se mantiene equidistante de las convicciones de unos y otros, pues de lo contrario reduciría a una parte a la condición de ciudadanos de segunda categoría.

Consideremos ahora las condiciones que han de cumplir las comunidades religiosas para poder embarcarse en un diálogo fecundo con la razón secularizada. ${ }^{25}$ Las comunidades de fe tradicionales han de enfrentarse al desafío que para ellas representan ciertos hechos específicamente modernos, como el pluralismo religioso, el desarrollo de las ciencias y la consolidación del derecho y la moral fundados en la razón. En primer lugar, los ciudadanos creyentes deben aceptar la legitimidad del pluralismo confesional que hoy se registra en las sociedades modernas, y han de establecer una relación reflexiva entre sus propias convicciones y las ajenas, sin que ello implique, claro está, la renuncia a la pretensión de verdad de la fe que cada cual profese. En segundo lugar, han de respetar la plena autonomía de la investigación científica, formulando los contenidos dogmáticos de su fe de un modo que muestre su compatibilidad con los resultados alcanzados por las ciencias. Por último, los ciudadanos creyentes han de asumir como logros irrenunciables los principios de libertad e igualdad entrañados en el derecho racional y en la moral universalista moderna.

Evidentemente, este triple cambio de actitud no puede imponerse desde fuera, sino que ha de producirse en la propia conciencia religiosa. En la cultura occidental, se han producido decisivos avances en esta dirección desde los tiempos de la Reforma y la Ilustración. La teología, y en parte también la filosofía de la religión, han asumido el protagonismo en esta tarea. En el caso católico, el concilio Vaticano II supuso un importante punto de inflexión, pero el propio Habermas observa que, al menos en Alemania, la actitud de las iglesias protestantes hacia la Modernidad no era, hasta muy entrado el siglo XX, muy distinta de la católica.

En la medida en que los ciudadanos que no profesan una religión renuncien al laicismo y los ciudadanos creyentes acepten confrontar su fe con las exigencias de la Modernidad, estarán dadas las condiciones para el proceso de aprendizaje recíproco postulado por Habermas. Este proceso habrá de adoptar la forma de un ensayo de "traducción" de los contenidos normativos de las tradiciones religiosas a un lenguaje secular, es decir, un lenguaje que no sólo sea accesible a los creyentes; en el entendido de que esta labor de traducción es una tarea cooperativa en la que participan por igual ciudadanos creyentes e increyentes. Pero este requiere alguna explicación.

El Estado liberal que no padezca una deformación laicista habrá de permitir la presencia de aportaciones específicamente religiosas en los debates sobre cuestiones socialmente controvertidas que se desarrollen en el nivel espontáneo o informal de la vida política. Sin embargo, para que esas aportaciones sean tenidas en cuenta en las deliberaciones formales de los órganos legislativos y de gobierno, han de ser previamente formuladas en un lenguaje secularizado, ya que en el Estado liberal todas las normas legales y decisiones políticas han de ser expresadas y justificadas en un lenguaje accesible a todos los ciudadanos. Hasta ahora, eran únicamente los ciudadanos creyentes quienes cargaban con la tarea de traducir a un lenguaje común sus argumentos religiosos, supuesto que desearan proporcionarles el apoyo de la mayoría. La propuesta de Habermas de que también los ciudadanos que no profesan una religión participen activamente en ese proceso de traducción se funda sobre todo en

25 Cf. J. Habermas, Zwischen Naturalismus und Religion, Suhrkamp, Frankfurt, 2005, pp. 143s. 
dos motivos. El primero es que si el esfuerzo de traducción recae sólo sobre los ciudadanos creyentes, éstos se sentirán discriminados, pues sólo a ellos se les exige un esfuerzo de adaptación que a los demás se les ahorra. En efecto, sólo a los ciudadanos creyentes se verían forzados a dividir su identidad en una parte privada, marcada por la condición de creyentes, y una parte pública, a lo que sólo transciende lo expresable en categorías comunes a todos. Este trato desigual genera resentimiento y corroe los lazos de la solidaridad social. El segundo motivo por el que los ciudadanos no religiosos han de participar en ese proceso de traducción es que, si se abstuvieran de hacerlo, acaso estarían privando al conjunto de la sociedad, y por tanto a sí mismos, de importantes recursos normativos que podrían ayudar a evitar el descarrilamiento de la Modernidad.

Habermas ha propuesto algunos ejemplos interesantes del modo como la razón moderna puede beneficiarse del diálogo con la religión que busca la traducción de percepciones morales presentes en ésta. Un primer ejemplo se refiere a la contribución que han realizado algunas tradiciones religiosas a debates de gran actualidad en el campo de la bioética. Ya se mencionó anteriormente que los avances de la investigación genética inauguran para la técnica humana un horizonte de posibles modificaciones eugenésicas del genoma individual, horizonte que Habermas contempla con gran preocupación. ${ }^{26}$ Manipulando el proceso de combinación azarosa de los cromosomas paternos, unos hombres podrían determinar de acuerdo con sus propias preferencias los rasgos físicos o psíquicos de quienes han de nacer. A este tipo de intervenciones eugenésicas se ha opuesto a menudo la conciencia religiosa invocando la condición creatural del hombre, a quien según el relato bíblico Dios ha hecho a su imagen y semejanza. Pues bien, Habermas sostiene que no hace falta ser creyente para comprender que en ese relato se expresa una intuición moral irrenunciable. ${ }^{27}$ La clave está en el desnivel que media entre Dios y el hombre, desnivel constitutivo para el concepto mismo de creación. Precisamente porque en el relato bíblico es Dios quien crea al hombre, su acción creadora no puede verse como un atentado contra la libertad de la criatura, sino como el origen de esa libertad. En cambio, allí donde unos hombres, ayudados por la técnica, se arrogan el derecho de decidir cuál será la naturaleza de sus semejantes, surge un nuevo tipo de asimetría entre los seres humanos que atenta contra los principios de igualdad y libertad. Se atenta contra la igualdad porque algunos hombres, en vez de deber su naturaleza empírica a un Ser absoluto, se la deben a decisiones tomadas por otros hombres, con lo que quedan en un aspecto decisivo por debajo de éstos. Y se atenta contra la libertad porque la capacidad humana de autodeterminación presupone que el pie forzado que para cada uno de nosotros representa su propia naturaleza no tenga su origen en decisiones que quedan en manos de otros hombres y que tienden a convertirnos en meras prolongaciones de la voluntad ajena.

El segundo ejemplo de traducción que queremos considerar está relacionado también con los principios de libertad e igualdad. La Modernidad ha defendido estos principios con argumentos racionales. Pero, como vimos antes, el propio Habermas reconoce que la razón ilustrada presenta hoy síntomas de debilidad que podrían anunciar el fracaso del proyecto moderno. Así las cosas, merece la pena prestar atención a ciertas intuiciones morales que originalmente se articularon en el lenguaje de la religión. Pensemos en la expectativa cris-

26 Cf. J. Habermas, Die Zukunft der menschlichen Natur. Auf dem Weg zu einer liberalen Eugenik?, Suhrkamp, Frankfurt, 2001.

27 Cf. J. Habermas, Glauben und Wissen, pp. 29-31. 
tiana del Juicio Final. Cada uno de nosotros habrá de comparecer un día ante Dios para dar cuenta de su vida. Nadie podrá reemplazarnos: seremos juzgados uno a uno, como individuos libres y responsables de sus actos. Tampoco habrá acepción de personas: no se hará distingos entre poderosos y humildes, ya no habrá privilegios, sino que todos serán tratados de la misma manera. ¿Debemos rechazar esta idea como un resto de mentalidad arcaica? Habermas cree lo contrario: "De esta abstracción del Juicio Final surgió el nexo conceptual de individualidad e igualdad en el que todavía se apoyan los principios universalistas de nuestra constitución, por más que éstos estén adaptados a la falibilidad de la capacidad humana de juzgar"28.

\section{La genealogía de la razón moderna}

Debemos considerar ahora la objeción más importante que se ha hecho a esta propuesta de un proceso de aprendizaje mutuo entre religión y razón secularizada. El hecho de que Habermas considere que la traducción de contenidos normativos de la religión a un lenguaje secular es necesaria para evitar el descarrilamiento de la Modernidad ha llevado a muchos a pensar que estamos ante un caso claro de funcionalismo religioso. En este planteamiento, la religión sería apreciada, no por su valor intrínseco, sino únicamente como instrumento útil para frenar un proceso de descomposición social. Esto supuesto, cabe esperar que la razón secularizada pierda todo interés en dialogar con la religión tan pronto como se produzca una de estas dos circunstancias: o que desaparezca la amenaza social que ha motivado el recurso a la religión, o que se encuentre un sustituto de la religión que cumpla su función sanadora de la razón de un modo aún más eficaz. Es más, cada paso que se dé en el proceso de traducción propuesto nos irá acercando más y más a la ruptura del diálogo de la razón con la religión, ya que el proceso consiste en la progresiva absorción por parte de la razón secularizada de intuiciones morales articuladas hasta entonces en un lenguaje religioso, de suerte que la razón, una vez completada con éxito la tarea de traducción, ya no necesitará el original del que se traducía. Y tendríamos todos los motivos para entender la secularización, en su fase postsecular, en el sentido original del término: como expropiación de bienes eclesiásticos, que pasan a manos seculares.

Habermas ha salido al paso de esta objeción advirtiendo que su propuesta de diálogo con la religión no obedece únicamente a razones tácticas coyunturales. Es verdad que la situación de emergencia en que ha desembocado la Modernidad es lo que incita hoy a la razón ilustrada a recurrir al potencial normativo de las grandes tradiciones religiosas como a una tabla de salvación. Pero, a la vez, esa situación de emergencia, ese riesgo de que la Modernidad termine descarrilando, obliga a la razón moderna a reflexionar sobre su propia naturaleza, reflexión que ha de adoptar la forma de una reconstrucción de la génesis histórica (Entstehungsgeschichte) de la razón occidental. A juicio de Habermas, dicha reflexión desemboca en la adhesión a "la tesis de Hegel de que las grandes religiones forman parte de la historia de la razón misma" 29 . La importancia de esta tesis está a la vista: implica que el diálogo de la razón con la religión, por más que haya sido ocasionado por una situación

28 J. Habermas, Eine Art Schadensabwicklung. Kleine politische Schriften VI, Suhrkamp, Frankfurt, 1987, p. 120. 29 J. Habermas, Zwischen Naturalismus und Religion, pp. 12s. 
coyuntural, obedece en realidad a una necesidad interna de la propia razón. Es a esto a lo que se refiere Habermas cuando, en su diálogo con Ratzinger, afirma que la filosofía ha de estar dispuesta a aprender de las religiones, "pero no por razones funcionales, sino -recordando el éxito de sus procesos 'hegelianos' de aprendizaje- por razones de contenido"30. La autorreflexión filosófica reconoce, en efecto, que la religión es una "figura del espíritu" (Gestalt des Geistes) ${ }^{31}$ dotada de un potencial cognitivo propio, y se ve en la necesidad de aclarar el vínculo interno que liga a las tradiciones religiosas con el pensamiento moderno.

Para apoyar esta idea decisiva de que la religión forma parte de la historia de la razón, Habermas recuerda a menudo que tanto la filosofía como las grandes tradiciones religiosas nacieron hermanadas a mediados del primer milenio antes de Cristo, en el período bautizado por Jaspers como "Época Axial” (Achsenzeit). En este período se produjo en Grecia e Israel, también en China y en la India, una revolución en la "imagen del mundo" impulsada por la superación del pensamiento mágico y la devaluación del poder explicativo del mito. En la Época Axial se registran, en concreto, tres grandes novedades reflexivas. La primera es el nacimiento de la conciencia histórica, al hilo de la elaboración dogmática de doctrinas que se remontaban a las figuras de sus fundadores. La segunda es la contemplación del mundo y de la totalidad de las relaciones interpersonales desde un punto de vista transcendente, lo cual desemboca en la formulación de una moral universalista. La tercera novedad es la distinción entre el destino individual y el colectivo, y en consecuencia el surgimiento de una nueva conciencia de la responsabilidad personal. En opinión de Habermas, estas tres novedades han troquelado el modo como todavía hoy nos entendemos a nosotros mismos. De hecho, Modernidad europea ha continuado avanzando en las tres direcciones señaladas al agudizar la conciencia de la propia contingencia, desarrollar el universalismo igualitario en la moral y el derecho, y fomentar la individuación. ${ }^{32}$

Ciñéndonos a Occidente, un hito decisivo en la historia común de razón y religión fue la temprana simbiosis de la religión cristiana con la filosofía griega. En el marco de la llamada helenización del cristianismo, los Padres de la iglesia practicaron una "traducción no asimiladora" 33 de los contenidos de su fe al lenguaje de la metafísica. Con ello, estos teólogos, que eran a la vez filósofos, despertaron la sensibilidad y el interés por experiencias históricas y comunicativas que en realidad no podían ser vertidas por completo en el molde conceptual de la metafísica de la sustancia.

Aunque la ósmosis semántica entre religión y filosofía se prolongó durante siglos, las cosas comenzaron a cambiar con la revolución nominalista tardomedieval, que puso en tela de juicio el pensamiento metafísico esencialista y con ello contribuyó decisivamente al nacimiento de la cultura moderna. Con el paso del tiempo, la ciencia físico-matemática, punta de lanza de esa cultura, habría de rechazar las construcciones metafísicas recibidas, dando al traste con la síntesis de fe y razón elaborada desde san Agustín hasta santo Tomás. A partir de entonces se generaliza un fenómeno de amnesia parcial: la razón moderna reconocerá que la metafísica, ahora rechazada, forma parte de su propia genealogía, pero tenderá

30 Op. cit., p. 115.

31 J. Habermas, Nachmetaphysisches Denken II, p. 213.

32 Cf. op. cit. 108 s.

33 J. Habermas, "Ein Bewusstsein von dem, was fehlt", cit.

Daimon. Revista Internacional de Filosofía, $\mathrm{n}^{\circ}$ 70, 2017 
a considerar la religión como una realidad que le es ajena. Para las corrientes dominantes del pensamiento moderno, la sima que separa razón y religión se ha vuelto infranqueable.

Frente a esta amnesia genealógica, Habermas insistirá en que numerosos conceptos clave del pensamiento occidental fueron formulados por vez primera en el seno de las tradiciones religiosas. En efecto, "conceptos como persona e individualidad, libertad y justicia, solidaridad y comunidad, emancipación, historia, crisis, etc." ${ }^{34}$ dan testimonio del intenso proceso de traducción de contenidos específicamente religiosos al lenguaje de la filosofía a lo largo de la Antigüedad tardía. ${ }^{35}$ Todavía en el siglo XVIII, la filosofía absorberá contenidos religiosos en el marco conceptual de la ética y la filosofía de la historia. ${ }^{36}$ Que el proceso de traducción ha continuado hasta el presente, lo demuestran los casos del joven Bloch o de Benjamin, o más recientemente los de Levinas o Derrida. Y no podemos saber -en esto insiste muchas veces Habermas- si este proceso de traducción de contenidos semánticos de las religiones ha llegado a su fin, o si por el contrario la razón moderna podrá seguir bebiendo de esa fuente y encontrando en ella recursos normativos que le permitan vencer su propia debilidad.

Pero la conveniencia de que la razón secularizada se muestre abierta al diálogo con las tradiciones religiosas no sólo se justifica en el plano de la historia de las ideas, mostrando la raigambre religiosa de numerosos conceptos filosóficos. Habermas sostiene que el drenaje religioso de la cultura moderna ha dejado un vacío palpable en la conciencia contemporánea, vacío que no ha sido posible colmar con los solos recursos de la razón secularizada. Es éste un punto sobre el que el autor alemán ha vuelto una y otra vez. Es muy elocuente, por ejemplo, su relato de las peculiares circunstancias que acompañaron el sepelio del escritor suizo Max Frisch. Pese a la condición agnóstica del finado y de la mayoría de los asistentes a la ceremonia, ésta se celebró, por expreso deseo de Frisch, en la iglesia de San Pedro de Zúrich, su ciudad natal. ¿Por qué precisamente en una iglesia? Años después de asistir al sepelio, Habermas explicaba así este hecho sorprendente: "Es evidente que Max Frisch -un agnóstico que rechazaba todo credo religioso- sintió lo embarazoso de todas las formas de enterramiento no religioso, y mediante la elección de aquel lugar documentó públicamente el hecho de que la Modernidad ilustrada no ha encontrado un equivalente adecuado del tratamiento religioso del último rite de passage, el que pone término a la historia de una vida" 37 . Ya en su conferencia "Creer y saber", Habermas había escrito: "Como vuelve a mostrar hoy el trato desinhibido con la herencia bíblica, todavía no disponemos de un concepto adecuado para la diferencia semántica entre lo que es moralmente incorrecto y lo que es profundamente malo. [...] Los lenguajes secularizados que simplemente eliminan lo que en otro tiempo se quería decir, provocan malestar [Irritationen]. Cuando el pecado se transformó en culpa y la transgresión de los mandatos divinos en infracción de leyes humanas, algo se perdió" 38 . Y esto que se perdió la conciencia contemporánea lo echa de menos, pues todavía

34 J. Habermas, Nachmetaphysisches Denken II, p. 102.

35 Aunque no podemos ocuparnos de ello, es importante advertir que según Habermas el intento de dar forma lingüística a la experiencia de lo sagrado había comenzado mucho antes, antes incluso de la época axial: los más antiguos mitos liberan narrativamente contenidos semánticos hasta entonces encapsulados performativamente en las conductas rituales (cf. J. Habermas, "Wie viel Religion verträgt der liberale Staat?, Neue Zürcher Zeitung, 6 de agosto de 2012).

36 Cf. K. Löwith, Weltgeschichte und Heilsgeschehen, Kohlhammer, Stuttgart, 1953.

37 J. Habermas, "Ein Bewusstsein von dem, was fehlt", cit.

38 J. Habermas, Glauben und Wissen, p. 24. 
resuena en su interior el eco lejano de un tiempo en que lo poseyó. Habermas habla al respecto de "intuiciones propias reprimidas" 39 o "silenciadas" 40 . Supuesto que esas intuiciones forman parte del potencial semántico de las tradiciones religiosas y que no cabe excluir de antemano que sea posible traducirlas al lenguaje de la razón, se impone la necesidad de una razón anamnética que recuerde sus propios orígenes y restablezca el diálogo con la religión.

Pero volvamos a la objeción formulada al comienzo de este apartado. El reconocimiento de que en las grandes tradiciones religiosas se han articulado por vez primera intuiciones normativas valiosísimas no es suficiente para desactivar la objeción que estamos considerando, toda vez que la razón filosófica podría aspirar a reconstruir todas esas intuiciones en su propio lenguaje; una vez lograda esa reconstrucción, la razón no tendría por qué prolongar su diálogo con la religión, pues ya habría asimilado todo lo que le interesaba de ella. Kant y Hegel son citados por Habermas como ejemplos de este modo de proceder. El primero sólo acepta aquellos contenidos de la revelación capaces de pasar por el tamiz de la razón. El segundo ha intentado elevar el cristianismo al nivel del concepto. En uno y otro caso las religiones históricas no pasan de ser un estímulo para la reflexión filosófica, del cual cabe desentenderse una vez la razón ha absorbido cuanto en ellas hay de aprovechable.

Habermas, por su parte, se distancia expresamente de Kant y Hegel en este punto. Frente a la imagen de una razón prepotente que decide soberanamente qué es válido y qué ha de ser rechazado en las tradiciones religiosas, el pensamiento postmetafísico reconoce abiertamente la falibilidad de la razón moderna y por tanto se muestra dispuesto a aprender de otras formas de experiencia. Aun manteniéndose agnóstica, "la razón secular no puede erigirse en instancia que juzga sobre las verdades de fe" ${ }^{41}$, pues ella ve en la fe una realidad que le resulta opaca y que, por ello mismo, no puede ser negada o ignorada sin más. Valiéndose de una curiosa imagen, Habermas sostiene que la razón agnóstica "traza círculos" en torno al núcleo opaco de la experiencia religiosa, de modo análogo a como los traza en torno al núcleo impenetrable de la intuición estética. ${ }^{42}$ En uno y otro caso, ofrecer una explicación exhaustiva equivale a ignorar lo que había que explicar. No en vano cita Habermas un pasaje de Benjamin en el que la tesis de que la crítica artística tiene por misión trasladar la belleza al ámbito de la verdad desemboca en la afirmación de que la verdad no ha de entenderse “como desvelamiento que aniquila el misterio, sino como revelación" ${ }^{43}$.

\section{Referencias}

Benjamin, W. (1928), Ursprung des deutschen Trauerspiels, Rowohlt, Berlín.

Berger, P. (Hg.) (2005), The Desecularization of the World: A Global Overview, Eerdmans Publishing Company, Grand Rapids.

39 J. Habermas, "Wie viel Religion verträgt der liberale Staat?", cit.

40 J. Habermas, Nachmetaphysisches Denken II, p. 327.

41 J. Habermas, "Ein Bewusstsein von dem, was fehlt", cit.

42 Cf. J. Habermas, Zwischen Naturalismus und Religion, p. 150; cf. J. Habermas, Nachmetaphysisches Denken II, p. 126.

43 J. Habermas, Nachmetaphysisches Denken II, p. 213. La cita de Benjamin procede de su obra El origen del drama barroco alemán (cf. Ursprung des deutschen Trauerspiels, Rowohlt, Berlín, 1928). 
Casanova, J. (1994), Public Religions in the Modern World, Chicago University Press, Chicago.

Casanova, J. (2009), Europas Angst vor der Religion, Berlin University Press, Berlín.

Casanova, J. / Joas, H. (Hg.) (2010), Die umstrittene Moderne, Kohlhammer, Stuttgart, 2010.

Habermas, J. (1981), Theorie des kommunikativen Handelns, Suhrkamp, Frankfurt.

Habermas, J. (1987), Eine Art Schadensabwicklung. Kleine politische Schriften VI, Suhrkamp, Frankfurt.

Habermas, J. (1988), Nachmetaphysisches Denken, Suhrkamp, Frankfurt.

Habermas, J. (1997), "Vom Kampf der Glaubensmächte. Karl Jaspers zum Konflikt der Kulturen", en: Id., Vom sinnlichen Eindruck zum symbolischen Ausdruck. Philosophische Essays, Suhrkamp, Frankfurt, pp. 41-58.

Habermas, J. (2001), Glauben und Wissen, Suhrkamp, Frankfurt.

Habermas, J. (2001), Die Zukunft der menschlichen Natur. Auf dem Weg zu einer liberalen Eugenik?, Suhrkamp, Frankfurt.

Habermas, J. (2005), Zwischen Naturalismus und Religion, Suhrkamp, Frankfurt.

Habermas, J. (2007), "Ein Bewusstsein von dem, was fehlt. Über Glauben und Wissen und den Defaitismus der modernen Vernunft", Neue Zürcher Zeitung, 10 de febrero de 2007.

Habermas, J. (2012), Nachmetaphysisches Denken II: Aufsätze und Repliken, Suhrkamp, Frankfurt.

Habermas, J. (2012), “Wie viel Religion verträgt der liberale Staat?, Neue Zürcher Zeitung, 6 de agosto de 2012.

Joas, H. (2002) "Eine Rose im Kreuz der Vernunft", Die Zeit, 7 de febrero de 2002.

Knapp, M. (2008), "Glauben und Wissen bei Jürgen Habermas", Stimmen der Zeit 226, pp. 270-280.

Löwith, K. (1953) Weltgeschichte und Heilsgeschehen, Kohlhammer, Stuttgart.

Maly, S. (2005): "Die Rolle der Religion in der postsäkularen Gesellschaft", Theologie und Philosophie 80, pp. 546-565.

Schmidt, T.M. (2009): "Gibt es eine moderne Religion? Jürgen Habermas und die Idee der 'postsäkularen Gesellschaft'”, Forschung Frankfurt 2, pp. 64-67.

Spaemann, R. (2007), "Postsäkulare Gesellschaft”, en: W. Schweidler (Hg.), Postsäkulare Gesellschaft. Perspektiven interdisziplinärer Forschung, Alber Verlag, Múnich, pp. 65-75.

Thomalla, K. (2007), “Bedeutung und Grenzen der Habermas'schen Religionsphilosophie”, en: W. Schweidler (Hg.), Postsäkulare Gesellschaft, Alber Verlag, Freiburg / München, pp. 115-147. 